\title{
Clinicoradiological Evaluation and Correlation of High-Resolution Computed Tomography Findings with Type 2 Diabetes Mellitus in Coronavirus Disease-19 Patients
}

\author{
Sanjay Tukaram Thorat ${ }^{1}$, Niyti Vinod Kaila², Parikshit Gajanan Mankar ${ }^{3}$, \\ Radhika Ratanlal Bajaj ${ }^{4}$, Avanti Jayant Damle ${ }^{5}$, Vaibhav Vijay Rane ${ }^{6}$ \\ 1, 2, 3, 4, 5, 6 Department of Medicine, Krishna Institute of Medical Sciences \\ (Deemed to Be University), Karad, Maharashtra, India.
}

\section{ABSTRACT}

\section{BACKGROUND}

Type 2 diabetes mellitus (T2DM) has emerged as the leading comorbidity in patients with coronavirus disease 2019 (COVID-19). However, data obtained on the correlation between the incidences of T2DM with COVID-19 are limited. We wanted to assess the severity of patients with T2DM and COVID-19, and study the correlation between the high-resolution computed tomography (HRCT) findings and hyperglycaemia with disease severity.

\section{METHODS}

This cross-sectional study included 100 patients with a history of diabetes and diagnosed COVID-19 positive. Data were collected using a semi-structured questionnaire. $\mathrm{P}<0.05$ was considered statistically significant.

\section{RESULTS}

The mean age was $58.81 \pm 11.43$ years with male preponderance $(71 \%)$. The difference was statistically significant in mean glycated haemoglobin (HbA1c) (7.32 $\pm 1.39 \%, \mathrm{P}<0.001$ ), mean high - density lipoprotein (HDL ; $39.78 \pm 6.76 \mathrm{mmol} / \mathrm{L}$ ), low - density lipoprotein (LDL; $63.23 \pm 13.36 \mathrm{mmol} / \mathrm{L}$ ), and triglyceride (TG; $140.70 \pm 43.57 \mathrm{mg} / \mathrm{dL}$ ) levels $(\mathrm{P}<0.05)$ in different CT severity score. Mean HbA1c $(\mathrm{P}<0.001)$, LDL, and CT severity scores $(\mathrm{P}=0.034$ and $\mathrm{P}<0.001)$ were highly significant in patients who died than the discharged patients. A significant positive correlation was seen between CT severity score with HbA1c, LDL, and TG levels and chances of death $(\mathrm{P}<0.001)$ rates, and also between the patients who died and HbA1c $(\mathrm{P}<0.001)$ and LDL $(\mathrm{P}=0.034)$ levels and CT severity score $(\mathrm{P}<0.001)$.

\section{CONCLUSIONS}

Ideal management of the metabolic equilibrium of glucose was crucial in assuring an improved clinical outcome. Increased surveillance was warranted for diabetic COVID-19 patients.

\section{KEY WORDS}

COVID-19, Glycated Haemoglobin A, Hyperglycaemia, Severe Acute Respiratory Syndrome Coronavirus 2
Corresponding Author: Dr. Parikshit Gajanan Mankar, Krishna Hospital, Karad, Maharashtra, India.

E-mail: mankarparig@gmail.com

DOI: $10.14260 /$ jemds $/ 2021 / 658$

How to Cite This Article:

Thorat ST, Kaila NV, Mankar PG, et al. Clinicoradiological evaluation and correlation of high - resolution computed tomography findings with type 2 diabetes mellitus in coronavirus disease-19 patients. J Evolution Med Dent Sci 2021;10(37): 3242-3246, DOI:

10.14260/jemds/2021/658

Submission 10-05-2021,

Peer Review 24-08-2021,

Acceptance 30-08-2021,

Published 13-09-2021.

Copyright (C) 2021 Sanjay Tukaram Thorat et al. This is an open access article distributed under Creative Commons Attribution License [Attribution 4.0 International (CC BY 4.0)] 


\section{BACKGROUND}

The rapid outbreak of coronavirus disease 2019 (COVID-19), which resulted from severe acute respiratory syndrome coronavirus 2 (SARS-CoV-2) infection has resulted in a public health emergency of international concern. ${ }^{1}$ COVID-19 has contributed to a huge adverse impact globally. COVID-19 infections can lead to diverse clinical outcomes from asymptomatic to severe life-threatening course or even death. ${ }^{2}$ Based on the evidence of rapidly increasing incidence of infections and the probability of asymptomatic carriers transmission, SARS-CoV-2 can be transmitted effectively among humans and exhibits a high potential for a pandemic. ${ }^{3-}$ 6 COVID-19 is distinguished by quick onset of symptoms which may include fever, fatigue, cough, dyspnoea, and chest tightness. ${ }^{4}$ A notable impact of comorbidities of chronic diseases on the clinical consequences in patients with COVID19 infection has been suggested by evidence. According to COVID-19 reports from the Centres for Disease Control and Prevention of the US Department of Health and Human Services, type 2 diabetes mellitus (T2DM) and metabolic syndrome patients may have up to 10 times higher risk of death when infected with COVID-19.7 T2DM is a common chronic metabolic disease. In India, there are about 69.2 million people with diabetes and are expected to cross 123.5 million by $2040 .{ }^{8}$

T2DM and the associated microvascular and macrovascular complications are the leading causes of mortality and morbidity all over the world. The incidence of contracting infections is more in T2DM patients as it has a clear cut compromised immune dysfunction, which might be accounted for multiple complications. ${ }^{9}$ Respiratory infections like pneumonia, tuberculosis and influenza are more common and more serious in older people with T2DM. ${ }^{10}$ Diabetes mellitus is a chronic inflammatory state having multiple metabolic and vascular abnormalities which may alter host response to pathogens. Increased synthesis of cytokines, oxidative stress and adhesion molecules promoted by hyperglycaemia and insulin resistance may lead to a higher predisposition to infections in T2DM patients. ${ }^{11}$ The clinical and imaging manifestations are particularly important in the preliminary stages of COVID-19. Chest computed tomography (CT) scans, particularly the high-resolution computed tomography (HRCT) scans help in diagnosing patients with COVID-19 infections in an early stage when clinical symptoms may be non-specific. ${ }^{12,13}$ They also have significant prognostic importance, especially in co-morbid patients. These can be employed to confirm the diagnosis, adjust the treatment plan, and predict clinical recovery or progression of disease in patients with COVID-19 infection, particularly those with T2DM.

The prevalence of diabetes in India is high, and there is a paucity of literature on its association with COVID-19. This warrants identification of factors responsible for the severe outcome in such patients. Hence, the present study intended to assess the severity of patients with diabetes and COVID-19 and correlate HRCT findings and hyperglycaemia with disease severity.

\section{METHODS}

A cross-sectional study was carried out on 100 COVID-19 patients who were admitted to the hospital for 6 months from May 2020 to October 2020 at the Department of Medicine in a tertiary care hospital and teaching institute in a metropolitan city in Western Maharashtra. Patients of both genders aged more than 18 years with a history of diabetes diagnosed as COVID-19 positive were included in the study. Patients with other critical illnesses, type 1 diabetes mellitus, and patients who were unwilling to participate in the study were excluded. The sample size was based on the assumption of a moderate positive correlation of 0.3 between CT severity score and hyperglycaemia with a $5 \%$ level of significance and $85 \%$ power to attain a minimum sample size of 96 patients. Ethical clearance was taken from the institutional ethics committee.

\section{Statistical Analysis}

Data on CT severity grades were collected using a semistructured pre-tested questionnaire. The data collected were entered in Microsoft Excel and were represented in frequencies and percentages, charts, and graphs. Mean and standard deviation (SD) of quantitative variables were recorded. Appropriate statistical tests were applied using SPSS software version 21 for data analysis. The student's ttest was used for comparison wherever applicable. Pearson's correlation was used for correlation analysis and $\mathrm{P}<0.05$ was considered statistically significant.

\section{RESULTS}

A total of 100 COVID-19 patients admitted to the hospital were recruited for this study. The mean age of the study participants was $58.81 \pm 11.43$ years. There were 71 males (71\%) and 29 females (29\%) in this study. Mean glycated haemoglobin (HbA1c) of the study participants was $7.32 \pm$ $1.39 \%$, mean high-density lipoprotein (HDL) was $39.78 \pm$ $6.76 \mathrm{mmol} / \mathrm{L}$, mean low-density lipoprotein (LDL) was 63.23 $\pm 13.36 \mathrm{mmol} / \mathrm{L}$, and mean triglycerides (TG) was $140.70 \pm$ $43.57 \mathrm{mg} / \mathrm{dL}$, respectively. Based on the CT severity and age, mean age in patients with mild CT was $57.06 \pm 13.96$, moderate CT was $58.26 \pm 10.53$, and severe CT was $59.67 \pm$ 12.83 years, respectively.

Based on the CT severity grading, out of all participants, 46 cases had mild (46\%), 42 cases had moderate ( $42 \%$ ), and 12 cases had severe (12\%) lung involvement on HRCT (figure 1). A significant difference was observed in the mean HbA1c levels of the patients with different CT severity grades $(\mathrm{P}<0.001)$. Table 1 shows that mean HbA1c was found higher in severe and moderate patients as compared to mild grade patients.

A significant difference was observed in mean HDL, LDL, and TG levels in different CT severity score patients $(\mathrm{P}<$ 0.05). Mean HDL in mild severity cases was higher as compared to the moderate and severe CT severity grades. In terms of LDL levels, mean LDL in mild severity cases was lower than moderate and severe cases. Similarly, mean TG levels in mild severity cases were lower than moderate and 
severe cases. The overall results showed that in the severe group, mean HDL was lowest and mean LDL and TG levels were highest in comparison to mild and moderate groups (table 2).

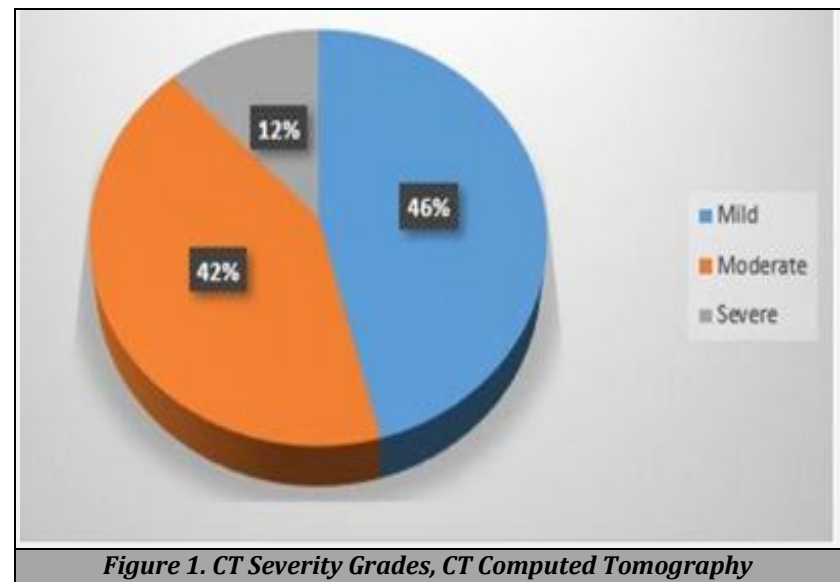

\begin{tabular}{|cc|}
\hline CT Severity Grade & HbA1c (\%) Mean \pm SD \\
Mild & $6.55 \pm 0.61$ \\
Moderate & $7.36 \pm 1.39$ \\
Severe & $8.43 \pm 1.58$ \\
\hline $\mathrm{p}<0.001^{*}[\mathrm{t}$ test between mild and severe \& moderate and severe] \\
\hline \multicolumn{2}{|c|}{ Table 1. CT Severity and HbA1c } \\
\hline CT, Computed tomography; HbA1c, Hemoglobin A1c \\
${ }^{*} \mathrm{p}<0.05$ was considered statistically significant \\
\hline
\end{tabular}

\begin{tabular}{|cccc|}
\hline CT Severity Grade & $\begin{array}{c}\text { HDL (mmol/L) } \\
\text { (mean } \pm \text { SD) }\end{array}$ & $\begin{array}{c}\text { LDL (mmol/L) } \\
\text { (mean } \pm \text { SD) }\end{array}$ & $\begin{array}{c}\text { TG (mg/dL) } \\
\text { (mean } \pm \text { SD) }\end{array}$ \\
$\begin{array}{c}\text { Mild } \\
\text { Moderate }\end{array}$ & $41.29 \pm 6.08$ & $52.24 \pm 7.84$ & $132.29 \pm 32.12$ \\
$\begin{array}{c}\text { Severe } \\
\text { p-value [t test between } \\
\text { mild and severe \& } \\
\text { moderate and severe ] }\end{array}$ & $36.33 \pm 4.19$ & $64.97 \pm 13.29$ & $141.35 \pm 46.46$ \\
\hline \multicolumn{4}{|c|}{ Table 2. CT Severity and Lipids } \\
\hline $\begin{array}{l}\text { CT, Computed tomography; HDL, High - density lipoprotein; LDL, Low - density } \\
\text { lipoprotein; TG, Triglycerides } \\
* P<0.05 \text { was considered statistically significant }\end{array}$ \\
\hline
\end{tabular}

The difference observed in mean HbA1c levels, mean LDL levels, and mean CT severity score of patients who had died with respect to the prognosis of patients was statistically significant as compared to those patients who were discharged.

The mean HbA1c levels were highly significant $(\mathrm{P}<$ 0.001) in patients who died in comparison to those patients who were discharged. Similarly, the mean LDL levels and mean CT severity scores were also observed to be statistically significant $(\mathrm{P}=0.034$ and $\mathrm{P}<0.001)$ in patients who died than those patients who survived. Table 3 shows that the difference was statistically insignificant in terms of HDL and TG levels and age.

\begin{tabular}{|c|c|c|c|c|c|}
\hline Variables & Death / Discharge & $\mathbf{N}$ & Mean & Std. Deviation & P - Value \\
\hline \multirow{2}{*}{ HbA1c (\%) } & Death & 5 & 10.16 & 2.03 & $<0.001^{*}$ \\
\hline & Discharged & 95 & 7.20 & 1.27 & \\
\hline \multirow{2}{*}{$\begin{array}{c}\text { HDL } \\
(\mathrm{mmol} / \mathrm{L})\end{array}$} & Death & 5 & 36.20 & 4.02 & 0.228 \\
\hline & Discharged & 95 & 39.97 & 6.87 & \\
\hline \multirow{2}{*}{$\mathrm{LDL}(\mathrm{mmol} / \mathrm{L})$} & Death & 5 & 75.60 & 7.89 & $0.034^{*}$ \\
\hline & Discharged & 95 & 62.58 & 13.37 & \\
\hline \multirow{2}{*}{$\mathrm{TG}(\mathrm{mg} / \mathrm{dL})$} & Death & 5 & 162.60 & 35.73 & 0.253 \\
\hline & Discharged & 95 & 139.55 & 44.03 & \\
\hline \multirow{2}{*}{$\begin{array}{l}\text { CT severity } \\
\text { score }\end{array}$} & Death & 5 & 17.40 & 1.82 & $<0.001^{*}$ \\
\hline & Discharged & 95 & 8.55 & 4.66 & \\
\hline \multirow[b]{2}{*}{ Age (years) } & Death & 5 & 64.60 & 11.72 & 0.250 \\
\hline & Discharged & 95 & 58.51 & 11.46 & \\
\hline \multicolumn{6}{|c|}{ Table 3. Prognosis of the Patient } \\
\hline \multicolumn{6}{|c|}{$\begin{array}{l}\text { HbA1c, Haemoglobin A1c; HDL, High-density lipoprotein; LDL, Low-density } \\
\text { lipoprotein; TG, Triglycerides } \\
{ }^{*} \mathrm{P}<0.05 \text { was considered statistically significant }\end{array}$} \\
\hline
\end{tabular}

Pearson correlation between CT severity scores and different variables are presented in Table 4. A statistically significant positive correlation was noted between the CT severity score and HbA1c, LDL, and TG levels, and chances of death $(\mathrm{P}<0.001)$. Similarly, regarding death, a statistically significant positive correlation was observed between the patients who died and HbA1c $(\mathrm{P}<0.001)$ and LDL $(\mathrm{P}=0.034)$ levels and CT severity score $(\mathrm{P}<0.001)$. These results demonstrated that patients with higher CT severity scores had higher HbA1c, LDL, and TG levels and higher chances of death and patients with high HbA1c and LDL levels and CT severity scores had higher chances of death due to COVID-19 (table 4).

\begin{tabular}{|c|c|c|c|c|c|c|c|c|}
\hline \multicolumn{2}{|c|}{ Correlations } & \multirow{2}{*}{$\begin{array}{l}\text { Age } \\
0.088\end{array}$} & \multirow{2}{*}{$\begin{array}{l}\text { HbA1c } \\
0.537\end{array}$} & \multirow{2}{*}{$\begin{array}{l}\text { HDL } \\
-0.137\end{array}$} & \multirow{2}{*}{$\begin{array}{l}\text { LDL } \\
0.506\end{array}$} & \multirow{2}{*}{ TG } & \multirow{2}{*}{$\begin{array}{l}\text { CT Severity } \\
\text { Score } \\
1\end{array}$} & \multirow{2}{*}{$\begin{array}{l}\text { Death } \\
0.391^{*}\end{array}$} \\
\hline \multirow{3}{*}{\begin{tabular}{|c} 
CT \\
severity \\
score
\end{tabular}} & $\begin{array}{l}\text { Pearson } \\
\text { Correlation }\end{array}$ & & & & & & & \\
\hline & $\mathrm{p}$-value & 0.383 & $<0.001^{*}$ & 0.175 & $<0.001^{*}$ & 0.049 & & $<0.001^{*}$ \\
\hline & $\mathrm{N}$ & & & 100 & 100 & 100 & 100 & 100 \\
\hline \multirow{3}{*}{ Death } & $\begin{array}{l}\text { Pearson } \\
\text { Correlation }\end{array}$ & 0.116 & 0.445 & -0.122 & 0.212 & 0.115 & 0.391 & 1 \\
\hline & $\mathrm{p}$ - value & 0.250 & $<0.001 *$ & 0.228 & $0.034^{*}$ & 0.253 & $<0.001^{*}$ & \\
\hline & $\mathrm{N}$ & 100 & 100 & 100 & 100 & 100 & 100 & 100 \\
\hline \multicolumn{9}{|c|}{ Table 4. Pearson's Correlation } \\
\hline \multicolumn{9}{|c|}{$\begin{array}{l}{ }^{*} \text { Correlation is significant at the } 0.05 \text { level }(2 \text { - tailed). } \\
\text { CT, Computed tomography; HbA1c, Haemoglobin A1c; HDL, High-density lipoprotein; } \\
\text { LDL, Low-density lipoprotein; TG, Triglycerides } \\
{ }^{*} \text { p }<0.05 \text { was considered statistically significant }\end{array}$} \\
\hline
\end{tabular}

\section{DISCUSSION}

COVID - 19 is characterized by high morbidity and mortality particularly in patients with severe comorbidities like diabetes. Epidemiological data has revealed that diabetic patients are at higher risk of severe clinical outcomes of COVID-19. The presence of diabetes mellitus was observed to be independently associated with COVID-19 severity and increased mortality. ${ }^{14-17}$ Also, diabetes mellitus patients generally fall into higher categories of SARS-CoV-2 infection severity in comparison to those without diabetes mellitus. ${ }^{18,19}$ As a result, understanding the interactions between diabetes and COVID-19 will be crucial to help, protect, and manage people with diabetes or at high risk of metabolic dysfunction. Combining imaging assessments with clinical and laboratory findings could help identify SARS-CoV-2 infections early.

In the current study, mean HbA1c levels were highly significant $(\mathrm{P}<0.001)$ with different $\mathrm{CT}$ severity grades. Wu et al. reported mean HbA1c levels as $9.2 \%$ which was higher than the current study levels. Higher HbA1c levels could be associated with inflammation, hypercoagulability, and low arterial oxygen saturation $\left(\mathrm{SaO}_{2}\right)$ in COVID-19 patients. ${ }^{20}$ The mean HDL levels were lower in the severe group and mean LDL and TG levels were higher as compared to mild and moderate groups in the present study. Hu et al. reported reduced HDL levels and increased LDL levels in patients with COVID-19.21 The higher LDL and TG levels and lower HDL levels could be attributed to the fact that patients with such comorbidities are at higher risk for COVID-19.

In the present study with reference to the Pearson correlation, a significant positive correlation was observed between the CT severity score and HbA1c, LDL, and TG levels and chances of death. These results indicated that patients with higher CT severity scores have higher HbA1c, LDL, TG 
levels and higher chances of death. According to Wang et al. COVID-19 disease severity as assessed on CT severity score showed a positive correlation with hyperglycaemia and dyslipidemia, which is in line with the current study. ${ }^{22}$

The present study provides the first direct evidence supporting the frequency of the coexistence of T2DM in patients with COVID-19. Another novel finding in the present study is the potentiated severity in COVID-19 patients with metabolic comorbidities. Although previous studies have reported diabetes as one of the most common comorbidities in patients with SARS-CoV-2 infections, the pathophysiological consequence of the close association between diabetes and COVID-19 progressions remains elusive. ${ }^{23-25}$ Thus, the current study demonstrated that diabetes and its associated metabolic complications play a significant role in enhanced morbidity and mortality in COVID-19 patients.

\section{CONCLUSIONS}

As many countries continue to struggle with the COVID-19 pandemic while others begin to relax the norms with strict measures of social distancing, recognizing high-risk populations is crucial to successfully control this disease. Being vigilant on patients with diabetes and a raised $\mathrm{HbA1c}$ level, while permitting a more humane method to patients with the well-managed disease may manifest favourable outcomes in decreasing the social and economic burdens related to an unsystematic method. The authors found a strong correlation between COVID-19 severity and glycemic control. Strict sugar control is needed to prevent complications in COVID-19 patients. Moreover, once a vaccine is available, concentrating on those who are at the highest risk for severe COVID-19 will be crucial to efficiently control this disease.

\section{Limitations}

However, the current study has few limitations. Firstly, the study included data collection using a questionnaire, which could result in inaccurate and incomplete information and the rate of non - response could be high. Secondly, the sample size was relatively small. Therefore, the findings observed in this study warrant further validation through future studies with large sample size.

Data sharing statement provided by the authors is available with the full text of this article at jemds.com.

Financial or other competing interests: None.

Disclosure forms provided by the authors are available with the full text of this article at jemds.com.

\section{REFERENCES}

[1] Lai CC, Shih TP, Ko WC, et al. Severe acute respiratory syndrome coronavirus 2 (SARS - CoV - 2) and coronavirus disease - 2019 (COVID - 19): The epidemic and the challenges. Int J Antimicrob Agents 2020;55(3):105924.
[2] Bhandari S, Rankawat G, Bagarhatta M, et al. Clinicoradiological evaluation and correlation of CT chest images with progress of disease in COVID - 19 patients. J Assoc Physicians India 2020;68(7):34-42.

[3] Zhao S, Lin Q, Ran J, et al. Preliminary estimation of the basic reproduction number of novel coronavirus (2019 $\mathrm{nCoV}$ ) in China, from 2019 to 2020: a data-driven analysis in the early phase of the outbreak. Int J Infect Dis 2020;92:214-7.

[4] Huang C, Wang Y, Li X, et al. Clinical features of patients infected with 2019 novel coronavirus in Wuhan, China. Lancet 2020;395(10223):497-506.

[5] Carlos WG, Dela Cruz CS, Cao B, et al. Novel Wuhan (2019-nCoV) coronavirus. Am J Respir Crit Care Med 2020;201(4):P7-P8.

[6] Munster VJ, Koopmans M, van Doremalen N, et al. A novel coronavirus emerging in China-key questions for impact assessment. N Engl J Med 2020;382(8):692-4.

[7] Morbidity and Mortality Weekly Report: novel coronavirus reports. Atlanta: Centers for Disease Control and Prevention of U.S. Department of Health \& Human Services. Accessed on 19 Nov 2020. https://www.cdc.gov/mmwr/Novel_Coronavirus_Repor ts.html.

[8] International Diabetes Federation. IDF Atlas. 7th edition. 2020. [Last accessed on 2020 Sept 7].

[9] Ayelign B, Negash M, Genetu M, et al. Immunological impacts of diabetes on the susceptibility of Mycobacterium tuberculosis. J Immunol Res 2019;2019:6196532.

[10] Dooley KE, Chaisson RE. Tuberculosis and diabetes mellitus: convergence of two epidemics. Lancet Infect Dis 2009;9(12):737-46.

[11] Hussain A, Bhowmik B, do Vale Moreira NC. COVID-19 and diabetes: Knowledge in progress. Diabetes Res Clin Pract 2020;162:108142.

[12] Xie X, Zhong Z, Zhao W, et al. Chest CT for typical 2019 nCoV pneumonia: relationship to negative RT - PCR testing. Radiology 2020;296(2):E42-E5.

[13] Shi H, Han X, Jiang N, et al. Radiological findings from 81 patients with COVID - 19 pneumonia in Wuhan, China: a descriptive study. Lancet Infect Dis 2020;20(4):P42534.

[14] Holman N, Knighton P, Kar P, et al. Risk factors for COVID - 19 - related mortality in people with type 1 and type 2 diabetes in England: a population - based cohort study. Lancet Diabetes Endocrinol 2020;8(10):823-33.

[15] Grasselli G, Zangrillo A, Zanella A, et al. Baseline characteristics and outcomes of 1591 patients infected with SARS - CoV - 2 admitted to ICUs of the Lombardy region, Italy. JAMA 2020;323(16):1574-81.

[16] Yang J, Zheng Y, Gou X, et al. Prevalence of comorbidities and its effects in patients infected with SARS - CoV - 2: a systematic review and meta-analysis. Int J Infect Dis 2020;94:91-5.

[17] Zhu L, She ZG, Cheng X, et al. Association of blood glucose control and outcomes in patients with COVID - 19 and pre-existing type 2 diabetes. Cell Metab 2020;31(6):1068-77.e3.

[18] Carey IM, Critchley JA, DeWilde S, et al. Risk of infection in type 1 and type 2 diabetes compared with the general 
population: a matched cohort study. Diabetes Care 2018;41(3):513-21.

[19] Wu C, Chen X, Cai Y, et al. Risk factors associated with acute respiratory distress syndrome and death in patients with coronavirus disease 2019 pneumonia in Wuhan, China. JAMA Intern Med 2020;180(7):934-43.

[20] Wu L, Girgis CM, Cheung NW. COVID - 19 and diabetes: Insulin requirements parallel illness severity in critically unwell patients. Clin Endocrinol 2020;93(4):390-3.

[21] Hu X, Chen D, Wu L, et al. Declined serum high density lipoprotein cholesterol is associated with the severity of COVID - 19 infection. Clin Chim Acta 2020;510:105-10.

[22] Wang Z, Du Z, Zhu F. Glycosylated hemoglobin is associated with systemic inflammation, hypercoagulability, and prognosis of COVID - 19 patients. Diabetes Res Clin Pract 2020;164:108214.

[23] Guan W, Ni Z, Hu Y, et al. Clinical characteristics of coronavirus disease 2019 in China. N Engl J Med 2020;382(18):1708-20.

[24] Yang X, Yu Y, Xu J, et al. Clinical course and outcomes of critically ill patients with SARS - CoV - 2 pneumonia in Wuhan, China: a single-centered, retrospective, observational study. Lancet Respir Med 2020;8(5):47581.

[25] Zhang J, Dong X, Cao Y, et al. Clinical characteristics of 140 patients infected with SARS - CoV - 2 in Wuhan, China. Allergy 2020;75(7):1730-41. 